\title{
From the Editor of Sexuality and Disability: Special Issue-A Look at Sexuality and Medical Concerns in Turkey
}

\author{
Sigmund Hough
}

Published online: 2 February 2013

(C) Springer Science+Business Media New York 2013

As we start a new year, we have the opportunity to learn about current issues regarding sexuality and medical conditions in Turkey. In 2010, the population of Turkey was estimated to be 73.7 million, with a relatively young population that includes $26.6 \%$ within the $0-14$ age range. The population growth from 1990 to 2008 has been reported to be 16 million or $29 \%$. The literature on sexuality has been increasing over the years in efforts to provide knowledge and awareness, guidance towards standards of care for assessment and intervention, as well as, the enhancement of clinical and educational programs already in place.

In the March 2013 issue, examples of front-line topics include Sexual Dysfunction in women after Renal Transplantation; looking at sexual satisfaction and loneliness levels in patients with Hemodialysis in a Muslim community; Gynecological Cancer; Sexual Dysfunction and Type 2 Diabetes Mellitus; the relationships between Sexual FunctionBody Image-Body Mass Index among women; Vaginal Dryness and impact upon health in addition to Sexual Function; Obesity and Sexual Dysfunction; relationship between depression and perception of sexuality in patients with Type II Diabetes; Premenstrual and Menstrual complaints and suitable coping strategies in university settings to improve quality of life and school performance; Sexuality and Nursing Process-A literature review.

Sexuality and Disability continues to provide original impact articles addressing the mental health and medical aspects of sexuality in relation to rehabilitation, hospital, academic and community settings, publishing up-to-date articles, case studies, clinical practice reports, reviews, featured articles, historical articles, special grand rounds topics, brief research reports and survey data reports. Value benefit is provided to authors through worldwide electronic exposure and professional access, while readership gains from scholarly contributions to advance the field through research, best-practice and educational articles. The refined lens of individual contributions from the local and international community continues to deliver a wealth of information on the topic of sexuality and disability for the reader. Thank you for joining us.

S. Hough $(\bowtie)$

396 Washington Street, Suite 211, Wellesley Hills, MA 02481, USA

e-mail: Sigmund_Hough@hms.harvard.edu 